\title{
Directional sensitivity of differential pressure sensors of gas velocity used in manual gravimetric measurements of dust emissions from stationary sources
}

\author{
Jerzy Szulikowski, Przemysław Kateusz* \\ Silesian University of Technology, Poland \\ Faculty of Power and Environmental Engineering \\ Department of Heating, Ventilation and Dust Removal Technology \\ *Corresponding author’s e-mail: przemyslaw.kateusz@polsl.pl
}

\begin{abstract}
Keywords: directional sensitivity, differential pressure sensors of gas velocity, flue gas velocity measurements, dust emission measurements, Pitot tubes, zero pressure dust sampling probe.

Abstract: Manual measurements of distribution of gas velocity in conduits of flue gas installations using systems with differential pressure sensors of velocity are often performed for the requirements of determining emissions of dust pollutants from industrial process plants to the atmosphere. The aim is to determine an axial velocity profile. Flows in measuring sections are not always coaxial along the run of the duct; they are characterized by different directions of the velocity vector at various measuring points. The determination of actual directions of vectors of local velocities giving a guarantee of an accurate calculation of the axial velocity is often not possible from the technical point of view and the measurement of the velocity is carried out with the parallel setting of the sensor head in relation to the axis and the walls of the conduit. Then the knowledge of the directional sensitivity of the applied velocity sensor allows either to eliminate the axial velocity measurement error or to take it into account by the uncertainty of this measurement. For specific situations of two-dimensional variation of direction of the velocity vector, the directional sensitivity characteristics and in consequence the characteristics of error have been determined for three sensors adopted to tests: a zero pressure dust sampling probe with the anemometric function as an element of the gravimetric dust sampler and comparatively - two commonly used Pitot tubes: types S and L.
\end{abstract}

\section{Introduction}

Measurements of the amount of dust emitted to the atmosphere together with flue gases (after cleaning them) are brought to the determination of the emission mass concentration of dust in the gas $s$ and/or the so-called dust emission rate $E$ (being the flux of dust mass) - in the flow conduit (duct or stack) at the outlet to the atmosphere. Both of these parameters are the basis for assessment - in various aspects - of noxiousness of the source of dust pollutant emissions.

The key concentration of dust $s$ is determined by the measurement. The emission rate is calculated according to the formula $E=s \dot{V}$, where $\dot{V}$ denotes the volumetric gas flow rate in the conduit. This flow rate is calculated according to the relationship $\dot{V}=\bar{w} A$, in which $A$ is the area of the conduit cross-section and $\bar{w}$ is the average gas velocity in the direction of the duct axis. The latter - by means of a suitable averaging - is determined on the basis of the point profile of a x i a 1 velocity $w_{0}$, which is found by measuring.

A frequent method and at the same time a reference method of measuring the dust concentration $s$ is the manual gravimetric method based on collecting a dust carrying gas sample at representative points in the duct cross-section and determining the concentration of dust in it. Measurements of distribution of gas axial velocity in the duct accompanying this method are often performed with differential pressure sensors (EN 2001, PN-EN 2007, PN 1994). The classical in use are independent anemometric systems which in the manual version contain Pitot tubes. There are also cases in which gravimetric dust samplers are provided with Pitot tubes mounted on the dust sampling probe near to the aspiration nozzle. In some other - rarer - solutions, gravimetric dust samplers contain a special so-called zero dust sampling probe with the function of a velocity sensor.

Known from the rules of fluid mechanics, the principles of independent measurement of gas point velocity with use of a differential pressure sensor are provided e.g. in the ISO standard (2013) and its counterparts EN ISO (2013) and PN-EN ISO (2013), and also in another ISO standard (1994). They mention the necessity of keeping the practical alignment of a sensor with a direction of gas flow. The ideal situation occurs when the gas flow at the measuring point inside the 
duct is parallel to its axis and walls as well as when the setting of the axis of the sensor head is the same (see Fig. 1); the measured gas velocity $w_{\mathrm{m}}$ (provided by the measuring system) is then exactly the actual velocity $w$ (or velocity vector value) identical with axial velocity $w_{0}$. If gas does not flow ideally in parallel to the axis of the conduit and the angle $\alpha$ (in plus or in minus) determining a deviation of gas flow direction from the axis of the sensor head placed along the axis of the conduit is less than $15 \div 20^{\circ}$, the situation is considered permissible (without introducing corrections of measured velocity). When the above-mentioned angle is exceeded, the direction of gas flow must be identified and the sensor head axis must be set along it; then the measured velocity $w_{\mathrm{m}}$ (as the actual velocity $w$ ) multiplied by the cosine of the angle $\alpha$ provides the required axial velocity. Unfortunately, such a requirement to identify a local gas flow direction and next to appropriately set the sensor head in any flow situation, and thus generally in three-dimensional problem, cannot be met in the measuring practice from the technical point of view. The reason is that typical access ports, i.e. openings made in flow conduit walls, allow - for commonly produced and applied sensors - only the forward movement of the stem in the direction vertical to this wall (as in Fig. 1), and not arbitrary tilted, as well as the rotation movement of the stem. The only possible situation for seeking the direction of a vector of gas velocity $w$ is when deformation (variation) of the direction of this vector occurs only in the plane parallel to the conduit axis. Such a plane has been shown (for an example configuration of the conduits) in Fig. 2 and there it has been marked DP. Then it is possible to turn the sensor introduced perpendicularly to the wall and find the angle $\alpha$ (corresponding to the greatest value of the so-called measuring pressure difference taken from the sensor).

Measuring teams - for technical reasons, e.g. because of the lack of ideal flow stability or the necessity of limiting measurements in time - do not always seek the exact angle $\alpha$ at each measuring point. They only define the estimated range of angle value in the whole measuring section, and at

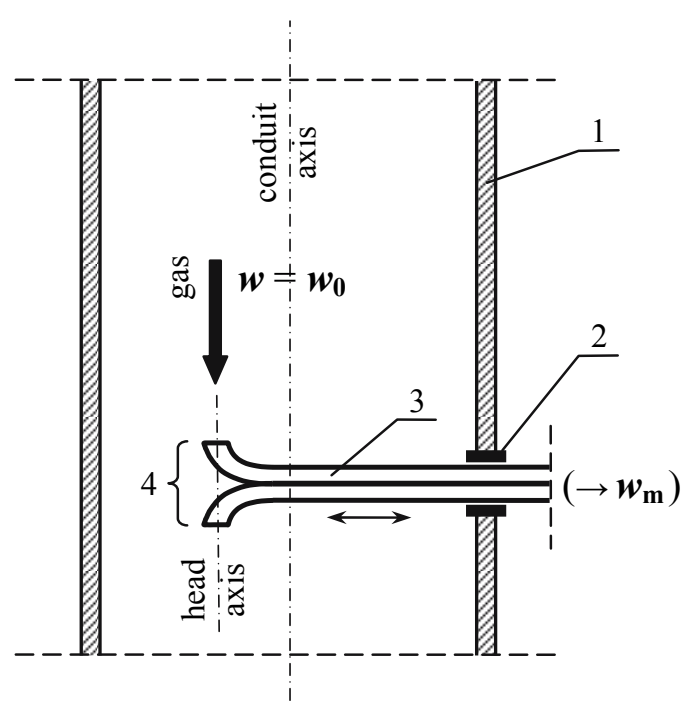

Fig. 1. Schematic illustration of the ideal measurement situation: of gas flow parallel to the axis and the wall of the conduit

1 - conduit wall, 2 - access port, 3 - velocity sensor stem, 4 - sensor head subsequent measurement points the sensor head axis is set parallel to the conduit axis (see Fig. 3). They must then know the corresponding extent of potential error of measurement of axial veloctiy $w_{0}$ (which is committed while having de facto only the measurement velocity $w_{\mathrm{m}}$ ), in order to estimate on its basis the uncertainty of measurement of $w_{0}$ (and in further sequence the uncertainties of: $\bar{w}, \dot{V}$ and $E$ ). The knowledge of the forming of the above mentioned measurement error of $w_{0}$ is to be provided through the relationship between $w$ and $w_{\mathrm{m}}$, that is the characteristic (most frequently in graphic form) of a given sensor referred to as directional sensitivity.

It should be added here that the binding Polish Standard (PN 1994), applicable to gravimetric measurement of the content of dust in flue gases, does not impose procedures for seeking the actual local gas inflow angle at measurement points; then estimating the potential error of measurement of $w_{0}$ on the basis of knowledge of the value $w_{\mathrm{m}}$ and the directional sensitivity of the applied sensor is practically essential.

Measurements of velocity with differential pressure sensors are also - apart from determining the volume flow rate in the entire measuring section - used to maintain the isokinetic rate and to identify distortion of flow direction of gas in the conduit in gravimetric measurements of dust concentration (the above-mentioned EN standard (2001) and its Polish version PN-EN (2007) and also the standard ISO (2003)). Here knowledge of the directional properties of these sensors may also be useful.

In the consideration of the issue of the directional properties of the zero sampling probe as a velocity sensor, it should also be remembered that the permissible - from the point of view of the phenomenon of collecting samples of dust-loaded gas - angle of its non-collinearity in relation to the direction of gas flow is accepted as $5^{\circ}$ or $10^{\circ}$ (EN 2001, ISO 2003, PN 1994); often for technical reasons it cannot be maintained.

Directional properties of classic Pitot tubes in general usage are known, however reports do not always state directly

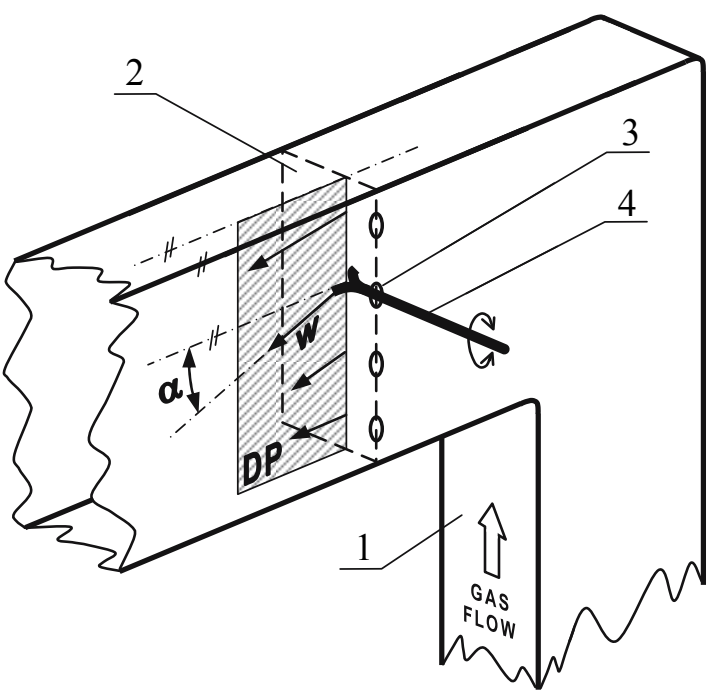

Fig. 2. Case of variation of gas velocity vector in planes parallel to conduit wall

1 - flow conduit, 2 - measuring section, 3 - access port, 4 - velocity sensor stem, DP - example of plane of deformation of velocity vector parallel to conduit wall 


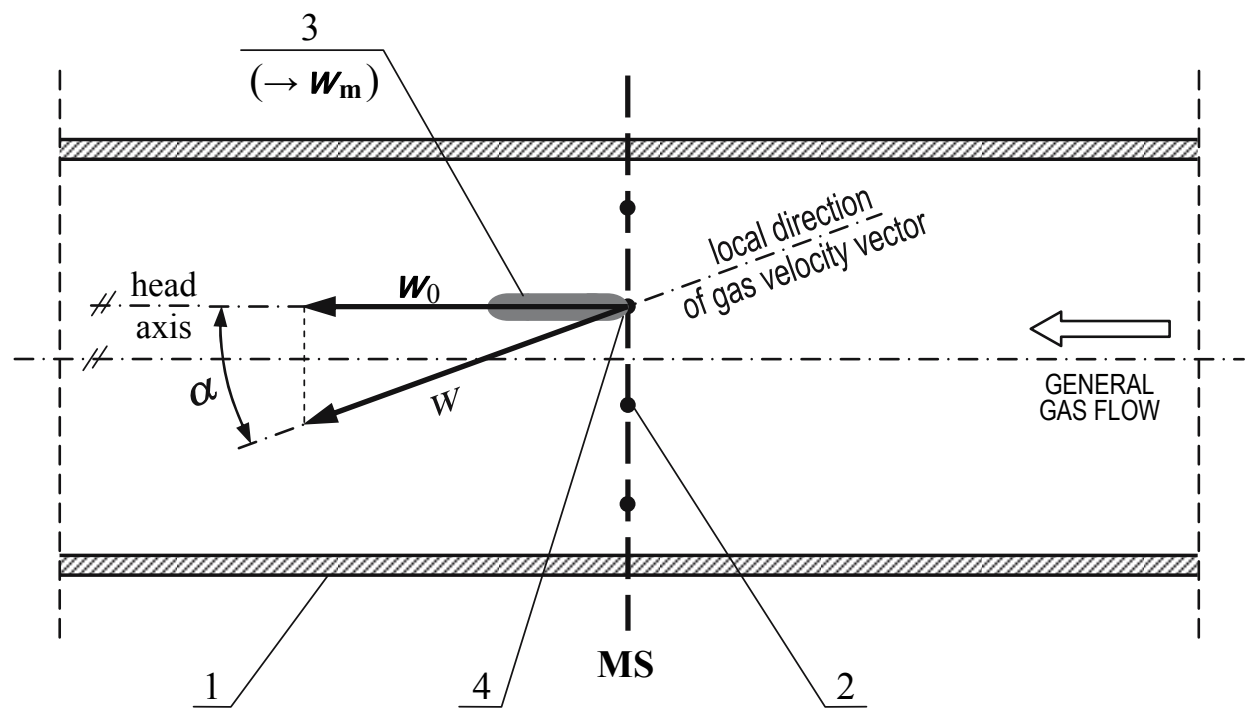

Fig. 3. Schematic illustration of the issue of accuracy of axial velocity measurement in situation of local gas flow deviation and setting the velocity sensor coaxially with the conduit, with gas velocity variation exclusively in plane parallel to conduit wall

1 - conduit wall, 2 - measurement points, 3 - velocity sensor head, 4 - sensor nose, MS - measuring section

in what relation the measured velocity $w_{\mathrm{m}}$ is to the axial velocity $w_{0}$, or do not always confirm the same levels of error. The very weak, several per cent directional sensitivity of S- and L-type Pitot tubes related to their deviations in the range of up to a dozen/thirty degrees from gas flow direction (Necati 1988, Kabza and Kostyrko 2003, Kołodziejczyk et al. 1974, Report 1979, Dwyer 2013 - to name only example sources) has been known for a long time now. For L-type tubes, according to Troskolański (1969) the accuracy of measurement of the actual velocity (that is the velocity vector magnitude) reaches the value of $1 \%$ at the above mentioned deviation being equal to $17^{\circ}$, and according to Ower and Pankhurst (1977) $2 \div 4 \%$ (depending on the shape of the nose) at a deviation of about $25^{\circ}$. The previously mentioned standards (EN ISO 2013, ISO 2013) bring e.g. differences in the velocity readings for S-type tubes and L-type tubes at $\alpha$ below approx. $15 \div 20^{\circ}$ amounting to not more than $1 \%$. The standard ISO (1994) indicates that the S-type tubes are more sensitive than the L-type tubes and they give a velocity error of less than $4 \%$ while not exceeding the angle $\alpha=15^{\circ}$, while the first - the error of approx. 3\% (operating according to the cosine of this angle). The same information related to S-type tubes is given in EN (2001). From the data in ISO (2008) it can be derived that the standard L-shaped tubes are characterized by the error of measurement of $w_{0}$ e.g. almost $3 \%$ at an angle of $20^{\circ}$ of non-coaxiality. According to one of the producers of the L-type tubes with the ellipsoidal nose (Test-Therm 2013) the measurement error of $w$ at the angle $\alpha$ below $12^{\circ}$ is less than $0.5 \%$.

The unusual pressure-type sensor, which the zero pressure dust probe is, until now has not been recognised in the objective issue at all.

The authors of this article decided to perform comparative tests of directional sensitivity for a zero pressure dust sampling probe and two known velocity sensor constructions of the $\mathrm{S}$ and $\mathrm{L}$ types - applied in complete systems for measuring emissions of dust pollutants. The result may be helpful above all in the precise estimation of global - i.e. taking account of many actual factors - accuracy (e.g. uncertainty) of measurements of flow rates and emission rates in industrial process plants.

\section{Object and range of research}

The object of tests is the directional sensitivity of a gas velocity measurement sensor in the conduit understood as the dependency of the quantity measured by the system with sensor, that is the measured velocity $w_{\mathrm{m}}$, on the angle of inflow of the gas measured in relation to the axis of the sensor head (parallel to the conduit axis) $\alpha: w_{\mathrm{m}}=\mathrm{f}(\alpha)-$ at the assumption, that angle $\alpha$ is only changed in the plane parallel to the conduit axis, as illustrated in Fig. 3. Knowledge of $w_{\mathrm{m}}$ enables to answer the question, how much it differs from the sought after axis velocity $w_{0}$. As a practical form of directional sensitivity in the interpretation of results of research conducted and reported here the dependency is assumed of

$$
w_{\mathrm{m}} / w=\mathrm{f}(\alpha)
$$

in which $w$ indicates the actual velocity of gas, i.e. the one which would be measured at the setting $\alpha=0^{\circ}$. The quotient $w_{\mathrm{m}} / w$ is in itself the re lat i ve (i.e. in reference to $w$ ) measured velocity of gas determined by the given measurement system (with a given sensor of velocity).

As a simple measure of deviation of measured velocity $w_{\mathrm{m}}$ from $w_{0}$ the ratio of both of these velocities $w_{\mathrm{m}} / w_{0}$ is assumed. Because between the axial velocity and the velocity vector magnitude there exists the obvious relationship $w_{0}=w \cos \alpha$, the above measurement deviation may be recorded as:

$$
w_{\mathrm{m}} / w_{0}=w_{\mathrm{m}} /(w \cos \alpha)=\mathrm{f}(\alpha)
$$

The relative error $\delta$ of the axial velocity measurement will then amount to:

$$
\begin{gathered}
\delta=\left(w_{\mathrm{m}}-w_{0}\right) / w_{0}=w_{\mathrm{m}} / w_{0}-1=w_{\mathrm{m}} /(w \cos \alpha)-1= \\
=\left(w_{\mathrm{m}} / w\right) / \cos \alpha-1=\mathrm{f}(\alpha)
\end{gathered}
$$


The dependence 2 is the function of the angle $\alpha$ both because of the occurrence of this angle's cosine and also because of the fact that $w_{\mathrm{m}}$ depends on $\alpha$.

The research has involved three differential pressure velocity sensors for flue gas (flowing through ducts or stacks of dust removal plants) used in various gravimetric dust sampler systems. The first is a zero pressure dust sampling probe as an element of the P-10ZA automatic gravimetric dust sampler device (serially produced in Poland). Above all it is used for the aspiration of samples of dust-loaded gas, but additionally - functioning with related electronic subassembly - it has a specific function of measuring gas velocity at the point of its location in the flow conduit. The second and third sensors are typical impact-pressure tubes: one S-type and one L-type.

The authors have already investigated the above-mentioned flue gas velocity sensors (Kateusz 2000, Kateusz et al. 2001, Kateusz et al. 2004, Szulikowski and Kateusz 2009). One of the aspects of these studies was the impact of gas flow turbulence on the metrological properties of the sensors. The level of turbulence intensity from approx. 10 to 19 per cent may be regarded as appropriate for gas flows in conduits with a developed turbulence, such as in industrial type installations.

Fig. 4 shows the tested zero pressure dust sampling probe. The dust sampling probe, in its part called head, has interchangeable aspiration nozzles with an inlet opening diameter $d_{\mathrm{a}}=10,13,16,20$ and $25 \mathrm{~mm}$. The inlet opening is on the nose of the dust sampling probe head. From two piezometric openings placed in specially chosen places: the internal IN and the external OU, two specific surface pressures are collected (in the case of the opening $\mathrm{OU}$ it is the static pressure in the conduit). They are given - through pressure connections at the end of the dust sampling probe stem and further through elastic tubes - to the internal micromanometer module in the central control unit of the dust sampler, which measures their difference (the so-called measuring pressure difference of the probe) $\Delta p$.
For the specific, unique function of the tested zero pressure probe, i.e. measurement of the velocity of gas flowing in a duct (and also for the other, key function of this probe being the automatic maintenance of isokinetic conditions of gas sampling), of fundamental significance is the aerodynamic characteristic of each of the probe nozzles that is the shaping of the measuring differential pressure of the probe $\Delta p$ depending on the velocity of gas $w$, when probe head axis is parallel to the direction of gas flow. This characteristic is recorded in the central unit of the dust sampler. The method of measurement of the velocity of flue gases in the conduits with the use of the discussed zero probe consists, in simplification, in measuring the $\Delta p$ value and using the reversed form of the aerodynamic characteristic, i.e. $w(\Delta p)$, by the central unit calculation module. This method and the aerodynamic characteristic itself are the results of previous research of the authors of this article, which they conducted for coaxial flows in relation to the axis of the conduit and the axis of the probe (Szulikowski and Kateusz 2009). Their other zero dust probe research (Kateusz et al. 2004) has indicated for all the aspiration nozzles a lack of influence of gas turbulence on the aerodynamic characteristic $w(\Delta p)$ - in the situation, when both the flow of gas and the setting of the aspiration nozzle are coaxial (i.e. parallel to the axis and the walls of the conduit), that is, when $w_{\mathrm{m}}=w=w_{0}$. For the four values of turbulence intensity $\varepsilon: 0.8,5,10$ and $14 \%$ there were no differences in courses of $w(\Delta p)$; in this range of gas turbulence intensity, there is the unambiguous measurement of velocity value $w$ of this gas regardless of turbulence differences.

The classic S- and L-type impact-pressure tubes, which also - for comparison with the zero probe - have been checked with regard to their directional properties in these tests, are presented in Figs 5 and 6. As in each of the generally known functions and applications of the sensors, from their two characteristic places two pressures are collected, which

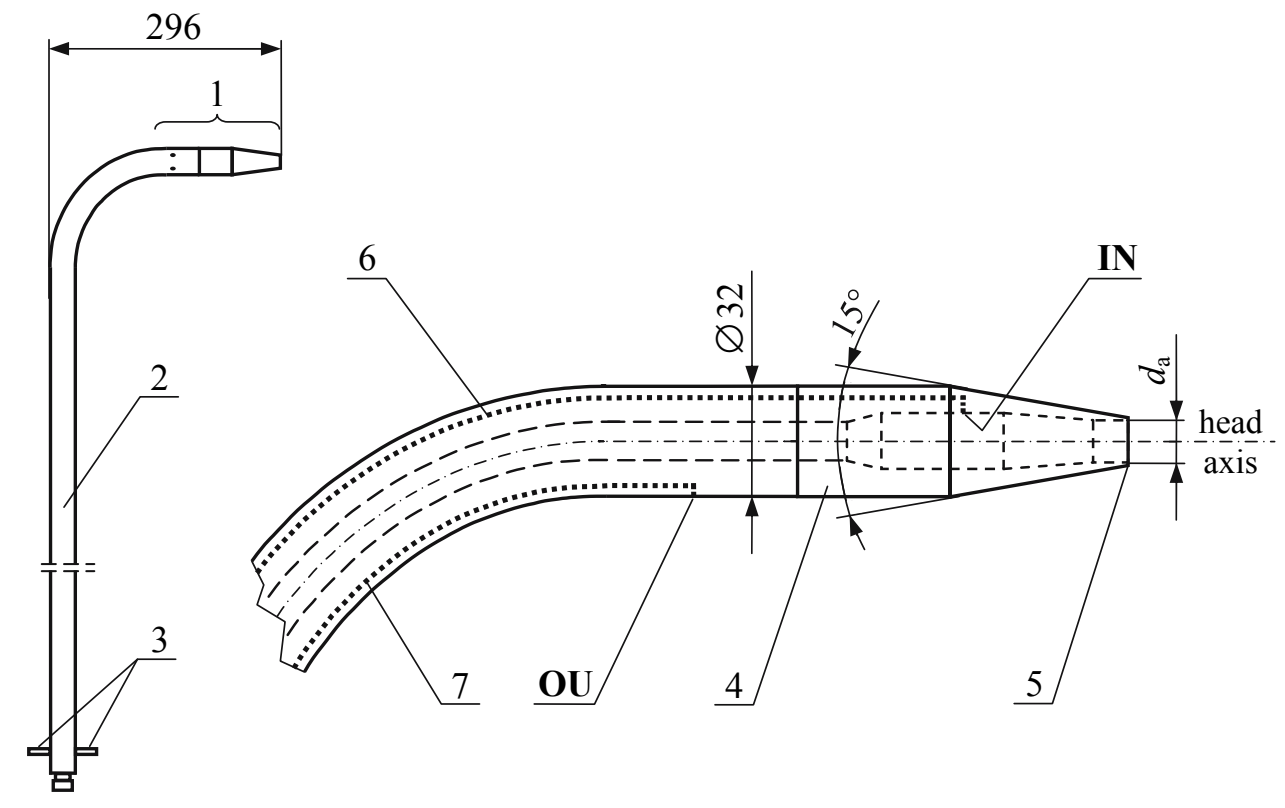

Fig. 4. Zero pressure probe under test

1 - head, 2 - stem, 3 - pressure connections, 4 - interchangeable aspiration nozzle, 5 - nose with inlet opening, 6 - conducting channel of inner pressure, 7 - conducting channel of outer pressure, IN - tap for receiving inner surface pressure, OU - tap for receiving outer surface pressure 


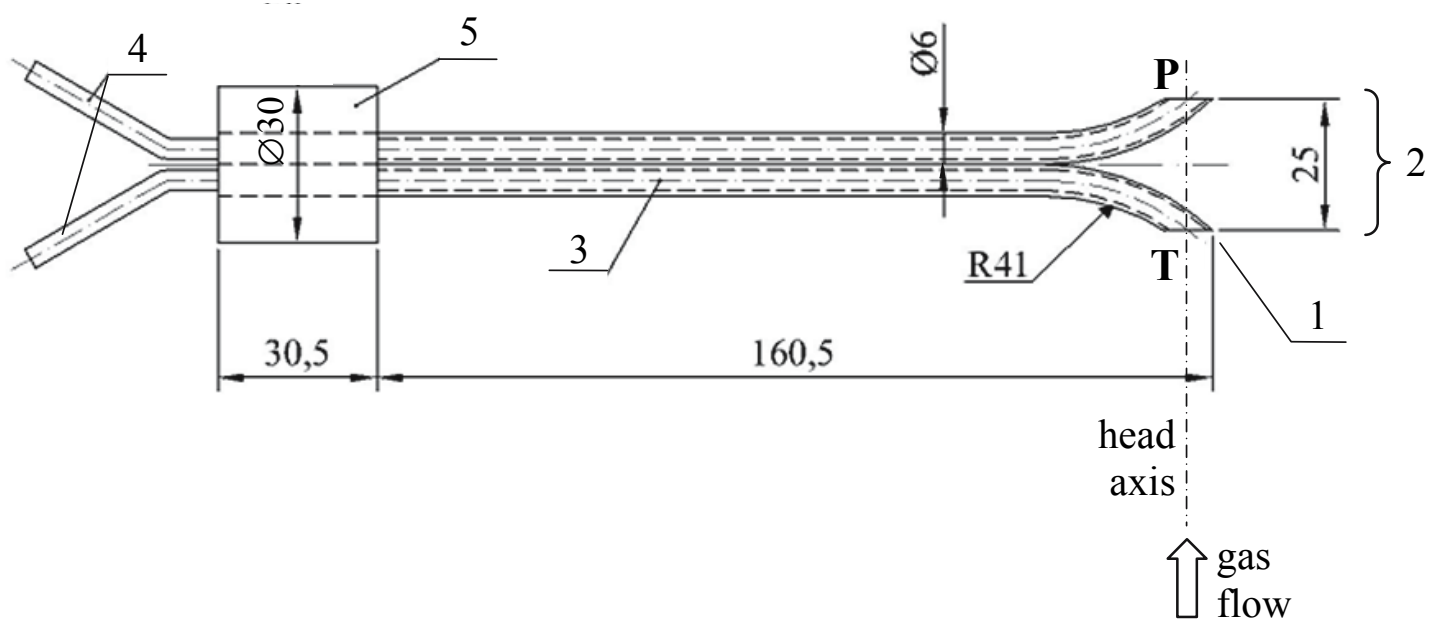

Fig. 5. S-type impact-pressure tube under test

1 - nose, 2 - head, 3 - tube $\varnothing 6 \times 1,4$ - pressure connections, 5 - rim for fastening the tube during the test, $\mathbf{T}$ - total pressure tap, $\mathbf{P}$ - 'wake' pressure tap

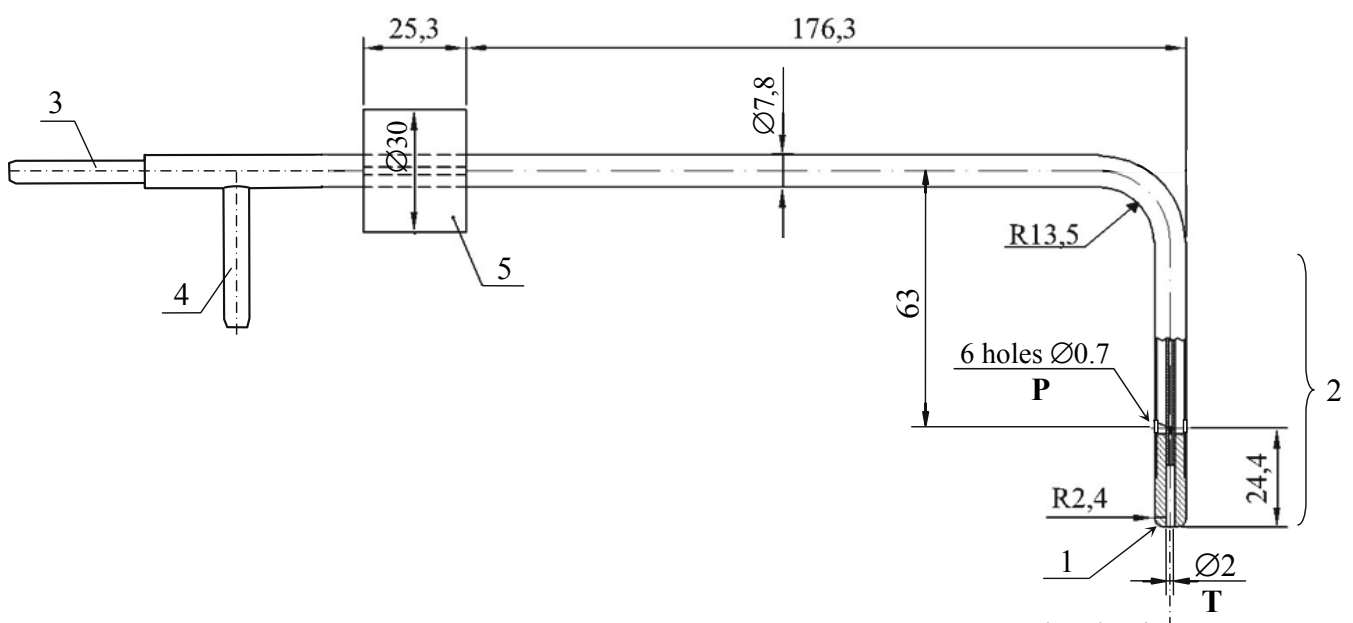

head axis !

Fig. 6. L-type impact-pressure tube under test

1 - nose, 2 - head, 3 - total pressure connection, 4 - static pressure connection, 5 - rim for fastening the tube during the test, $\mathbf{T}$ - total pressure tap, $\mathbf{P}$ - static pressure taps

compose their difference (called the measuring tube pressure difference) $\Delta p$ measured by the micromanometer. At the nose of each of both tubes, from the opening $\mathrm{T}$ (i.e. from the place of impact), the total pressure is taken. From the opening $\mathrm{P}$ in the case of the S-type tubes some surface pressure (with conversion of a part of dynamic pressure) in aerodynamic wake is tapped, while in the case of the L-type tube - static pressure is tapped. The relation which is the basis of the point velocity $w$ measurement (at the aligned setting of tube head and gas flow) is expressed - for instantaneous values of $w$ and $\Delta p$ or for non-turbulent flows - with the known formula:

$$
w=\sqrt{\frac{2 \Delta p}{\beta \rho}}
$$

in which $\rho$ designates gas density, and $\beta$ - empirical shape factor (for standard tubes according to ISO (2008) the shape factor amounts to 1 ; then the $\Delta p$ difference is identified with the dynamic pressure). Both tubes have their recognised values of factor $\beta$ in calibration testing, for the coaxial setting of tubes and gas flow. The tested S-type tube (Fig. 5) has e.g. for turbulent flow $\varepsilon=10 \%$ the factor $\beta$ with a mean value 1.45 (with certain dependence on the level of measured velocity $w$ ). For the tested L-shaped tube (Fig. 6) it amounts to 1.00 .

For turbulent flows, in which the read-out value $\Delta p$ reflects the averaging of velocity fluctuations, a precision correction is usually introduced giving the final formula 5 (Goldstein 1983, Ower and Pankhurst 1977, Kateusz et al. 2004, Kateusz 2000):

$$
w=\sqrt{\frac{2 \not p}{\beta \rho\left(1+\varepsilon^{2}\right)}}
$$

In all velocity calculations concerning the impact pressure tubes in this research, the above formula is applied. 
The previous research of the authors concerning the two above impact-pressure tubes, related to those discussed in this article, was carried out on the influence of turbulence of gas flowing coaxially on metrological characteristics of individually operating so-called 'compact' differential pressure probes (cylindrical tubes, S-type tubes and rhomboid tubes) (Kateusz et al. 2001) and also S-type tubes permanently connected with dust aspiration probes (Kateusz et al. 2004). It results from it that the shape factor $\beta$ of the S-type tubes depends both upon the intensity of gas turbulence, the velocity of which is measured through a system with this tube, and on the level of the measured velocity itself. A certain L-shaped tube, set coaxially to the gas flow, was applied in the tests reported by Kateusz (2000) and a lack of difference was recorded between the indications of this sensor for turbulence intensity $0.5 \%$ and $10 \%$ of this flow in a wide velocity range (from several to more than twenty $\mathrm{m} / \mathrm{s}$ ).

Having experience from the above quoted previous research, the authors took into consideration in this research the above mentioned features both of zero pressure probe and also S- and L-type tubes connected with external flow turbulence.

\section{Method and course of research}

Examination of three sensors was performed at the stand whose diagram is shown in Fig. 7. Into the open wind tunnel placed in the laboratory hall, air is introduced drawn through a fan from the interior of the hall. The main part of the tunnel is equipped with flow straighteners. After the nozzle with a specially selected outline profile, in a cross-section $224 \times 224 \mathrm{~mm}$ conduit is located a section of replaceable turbulizers. Through a combination of vertical and horizontal turbulizers in the form of rods of different shapes and dimensions of cross-sections, varied turbulence was created at the wind tunnel outlet in the range of its intensity $\varepsilon=0.8 \div 18 \%$. Flows of intensity $\varepsilon \geq 10 \%$ were typified by vortex macroscale of over $30 \mathrm{~mm}$ and microscale $5 \mathrm{~mm}$ (Kateusz 2000). At a short distance from the outlet of the square conduit, there is a measuring section in the open discharge stream. In it, the stream has a transverse uniform velocity profile. In the centre of the section were placed the noses of heads of the examined velocity sensors. A change of velocity value in discharge airstream was obtained by a variable flow rate of air in the tunnel, regulated by a fan frequency converter. Reference velocity $w$ measurement in the centre of the measuring section, carried out precisely at the time when the tested velocity sensor was placed in it, was achieved directly through a control L-shaped microtube, operating with a differential micromanometer, which measured the pressure difference $\Delta p$ that it received. For each turbulizer system the correlation dependency was known between the reference velocity $w$ and the indication of the control microtube $\Delta p_{c}$ : $w=\mathrm{f}\left(\Delta p_{\mathrm{c}}\right)-$ as a result of previous calibration with a reference AMCA type Pitot-static standard tube $\varnothing 6$ conforming with ISO (2008), which received dynamic pressure $p_{\mathrm{d}}$. The given correlation dependency serves to determine the reference velocity $w$.

The sensors were tested at $w$ velocities in the range $3 \div 31 \mathrm{~m} / \mathrm{s}$, covering encountered velocities in flow conduits of flue gas plants. Inside the discharge airstream were placed the absolute pressure, temperature and relative humidity sensors. In the case of the mounted system with the zero pressure probe, thermometer and manometer were inherent parts of the P-10ZA dust sampler (static pressure is received in the zero pressure probe). In the case of the system with the L-type tube and S-type tube, pressure and temperature measurements were performed by an independent meter (a specialized instrument for gas flows in conduits). Relative humidity was measured with a hair hygrometer. On the basis of the above mentioned parameters, the air density $\rho$ was calculated in a standard way. An appropriate support construction and angle meter enabled the rotary setting of sensors and in consequence the change and control of angle $\alpha$ between the sensor head axis and the horizontal axis of reference velocity vector from $-40^{\circ}$ to $+40^{\circ}$. In the direction of the sensor head axis velocity $w_{0}$ occurs. A measuring system with a differential micromanometer and with the given sensor measured pressure difference $\Delta p$, on the basis of which the value of the so-called measured velocity $w_{\mathrm{m}}$ was determined.

In Fig. 8 the measuring system with the zero pressure probe together with some elements (necessary here) of the P-10ZA dust sampler is shown diagrammatically. Outer and inner pressure connections of the probe surface were linked to the central control unit of the dust sampler. In its internal differential micromanometer module, the difference $\Delta p$ was measured and also the value of the measured velocity $w_{\mathrm{m}}$ was calculated according to procedure (generally valid for velocity

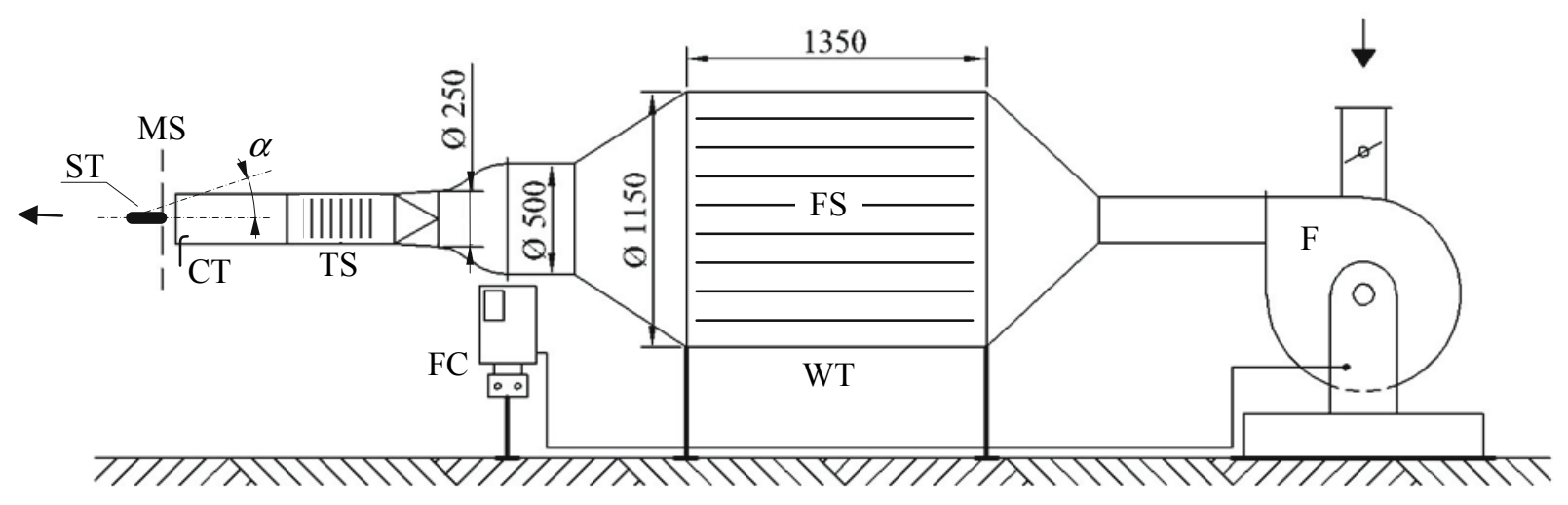

Fig. 7. General scheme of the test stand (in front view)

F - fan, FC - frequency converter (for fan resolution adjustment), WT - wind tunnel, FS - flow straightener, TS - turbulizers section, MS - measuring section, ST - sensor under test, CT - control microtube 


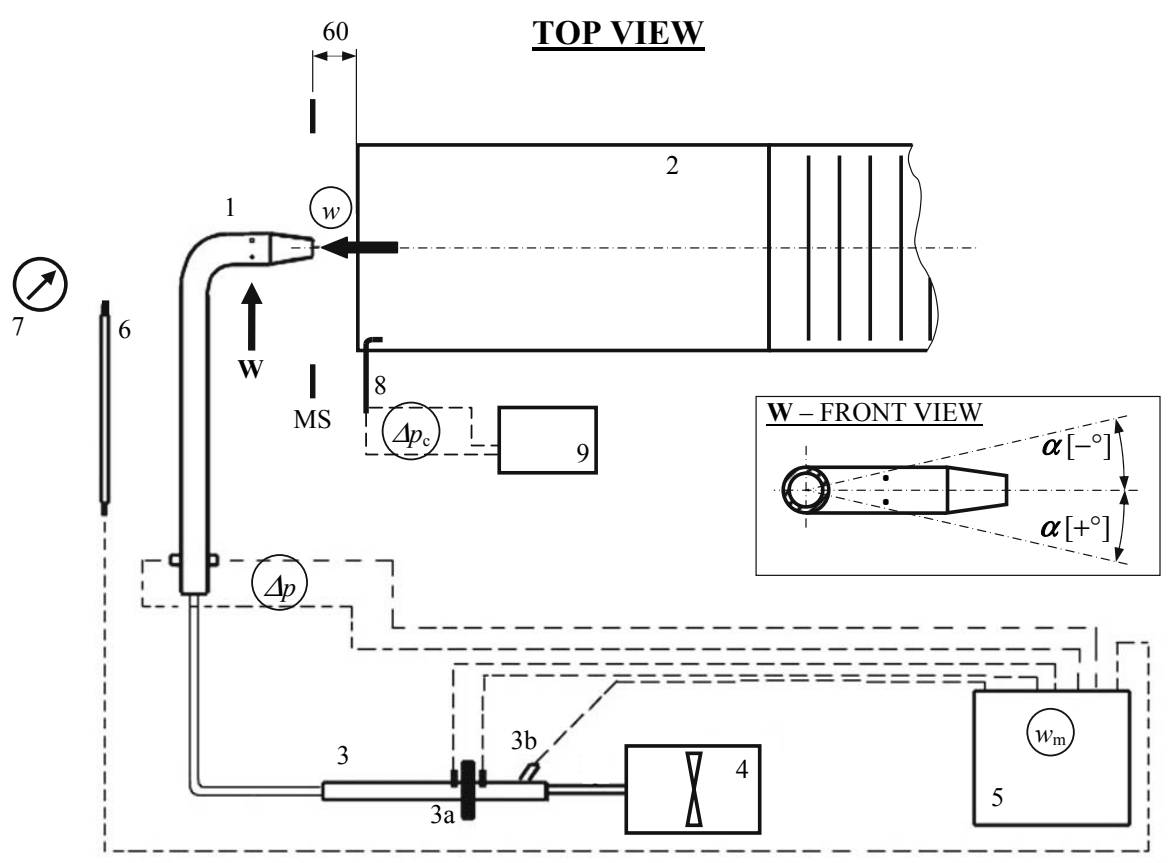

Fig. 8. System of measuring gas velocity with the zero pressure dust probe under test

1 -zero pressure probe, 2 - discharging section of the wind tunnel (with turbulizers), 3 - flow measuring orifice (with a quadrant orifice plate, 3a, and temperature sensor, $3 b$ ), 4 - gas pump, 5 - dust sampler central unit, 6 - thermometer sensor, 7 - hair hygrometer, 8 - control microtube, 9 - differential pressure micromanometer, MS - measuring section; (drawing not to scale)

$w$ at the coaxial setting of the probe) as described in the section "Object and range of research". The value $w_{\mathrm{m}}$ was displayed on the central unit screen. The values of air parameters in the stream, angle $\alpha$, velocity $w_{\mathrm{m}}$, intensity $\varepsilon$ (for a given mounted turbulizer system) were noted manually, as well as readings $\Delta p$ c of the control microtube. Air density $\rho$ and reference velocity $w$ were calculated (the former - based on the above-mentioned measured air parameters, the latter - by correlation dependence $w=\mathrm{f}\left(\Delta p_{\mathrm{c}}\right)$ appropriate for the given turbulizer system, that is for the given intensity of turbulence in the stream with the measuring section).

Fig. 9 shows schematically the measuring system with S- and L-type tubes. A given tube was connected to the differential micromanometer, to which two characteristic surface pressures where supplied, for which the difference $\Delta p$ was measured and noted. In further handling, on the basis of $\Delta p$ the velocity being the measured velocity marked $w_{\mathrm{m}}$ was calculated according to equation 5 (obligatory for the coaxial setting of tube head). Inserted into this formula was the value of the shape factor $\beta$ for the S-type tube that was appropriate for the given turbulence of the discharge stream and the given velocity level (and originated in the previously performed calibration tests described under equation 4). Measured and/or noted were also: air parameters in the stream, angle $\alpha$, intensity $\varepsilon$ (for a given mounted turbulizer system) and indications $\Delta p_{c}$ of the control microtube. Air density $\rho$ and reference velocity $w$ were calculated.

\section{Results of research}

\section{Preliminary results}

Investigation into the performance of the aspiration zero pressure probe as a velocity sensor first concerned the potential influence of the level of gas velocity $w$ on the directional characteristic $w_{\mathrm{m}} / w=\mathrm{f}(\alpha)$. Measurements performed within the framework of the MSc thesis (Tracz 2003) included all aspiration nozzles; for each of them the measured velocity value $w_{\mathrm{m}}$, determined by the probe system was observed with a reference velocity level $w$ varying in the range appropriate for a given nozzle, at the same turbulence intensity $\varepsilon=10 \%$. For nozzle $d=16 \mathrm{~mm}$ and turbulence $\varepsilon=10 \%$, Figs 10a, $10 \mathrm{~b}$ and $10 \mathrm{c}$ illustrate the characteristics $w_{\mathrm{m}} / w=\mathrm{f}(\alpha)$ at three levels of velocity $w: 7.7,10.9$ and $13.9 \mathrm{~m} / \mathrm{s}$. It may be seen that the velocity does not influence the shape of the curves $w_{\mathrm{m}} / w=\mathrm{f}(\alpha)$. The same regularity was noted for the remaining probe nozzles serving (in the P-10ZA dust meter) other ranges of velocity $w$ (for example: nozzle $d_{\mathrm{a}}=25 \mathrm{~mm}$ was examined in range $w=3.1 \div 5.4 \mathrm{~m} / \mathrm{s}$, and nozzle $d_{\mathrm{a}}=10 \mathrm{~mm}$ in range $w=19 \div 31 \mathrm{~m} / \mathrm{s}$ ).

Then two intensities of turbulence $\varepsilon$ were generated: 0.8 and $10 \%$, which enabled establishment of what influence on the directional characteristics of all nozzles is exerted by turbulence intensity. For each of the nozzles one velocity $w$ (from the centre of the range served by a given nozzle) was fixed in these tests. An example of the results - for $d_{\mathrm{a}}=20 \mathrm{~mm}$ and $w=6.8 \div 6.9 \mathrm{~m} / \mathrm{s}-$ is shown in Fig. 10d. Generally, the nozzles with large diameters $d_{\mathrm{a}}$, i.e. 20 and $25 \mathrm{~mm}$, are observed to have a clear influence of $\varepsilon$ on the curves $w_{\mathrm{m}} / w=\mathrm{f}(\alpha)$; for nozzles of small diameters $(10,13$ and $16 \mathrm{~mm})$ - the influence is less. In connection with the observation of this influence, for further treatment it was decided to accept the curves corresponding to the turbulence typical for real industrial gas duct flows, that is for $\varepsilon=10 \%$.

Recognition of directional behaviour of comparative - in relation to the zero pressure probe - S- and L-type tubes primarily concerned the influence of the level of gas velocity 


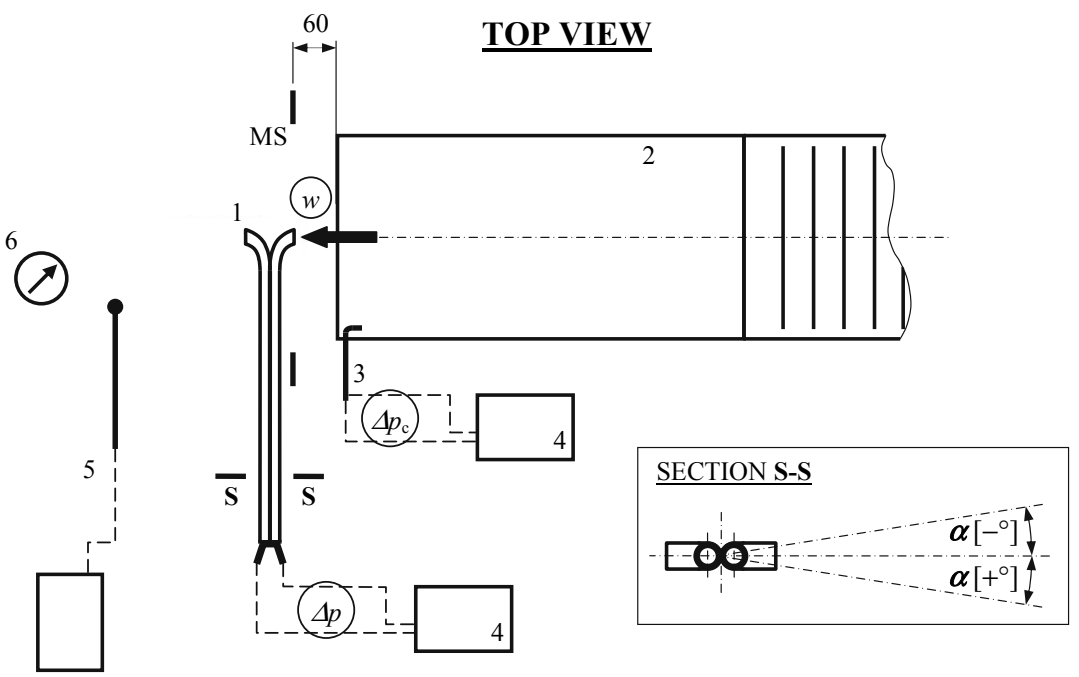

Fig. 9. System of measuring gas velocity with the S-type and L-type impact-pressure tubes under test 1 - S- or L-type tube (here: S-type as an example), 2 - discharging section of the wind tunnel (with turbulizers), 3 - control microtube, 4 - differential pressure micromanometer, 5 - temperature and absolute pressure meter, 6 - hair hygrometer, MS - measuring section; (drawing not to scale)
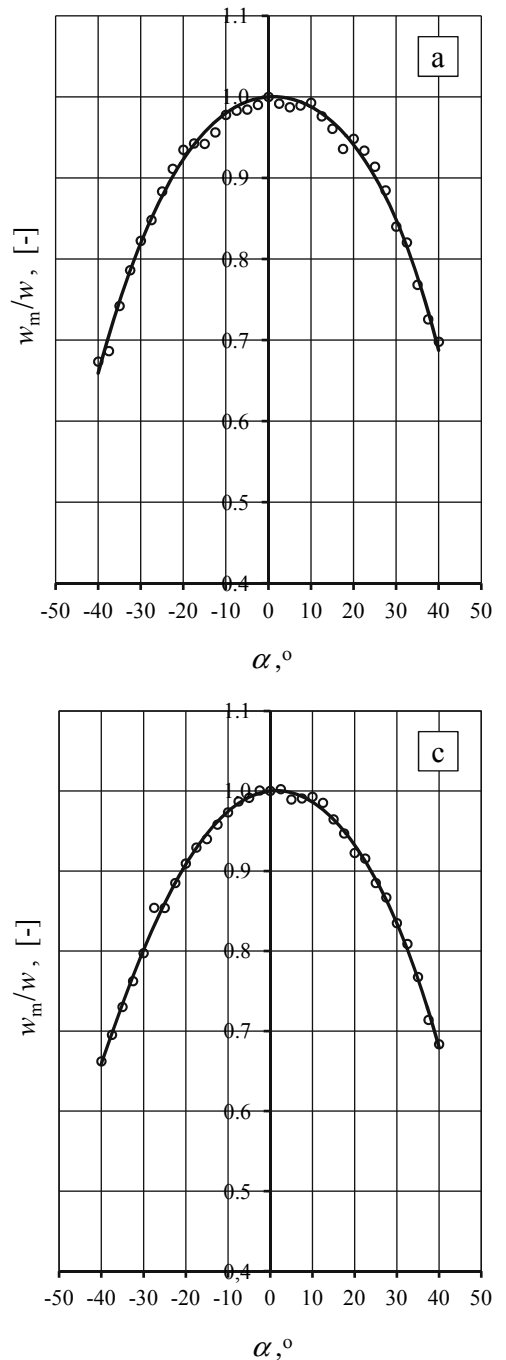
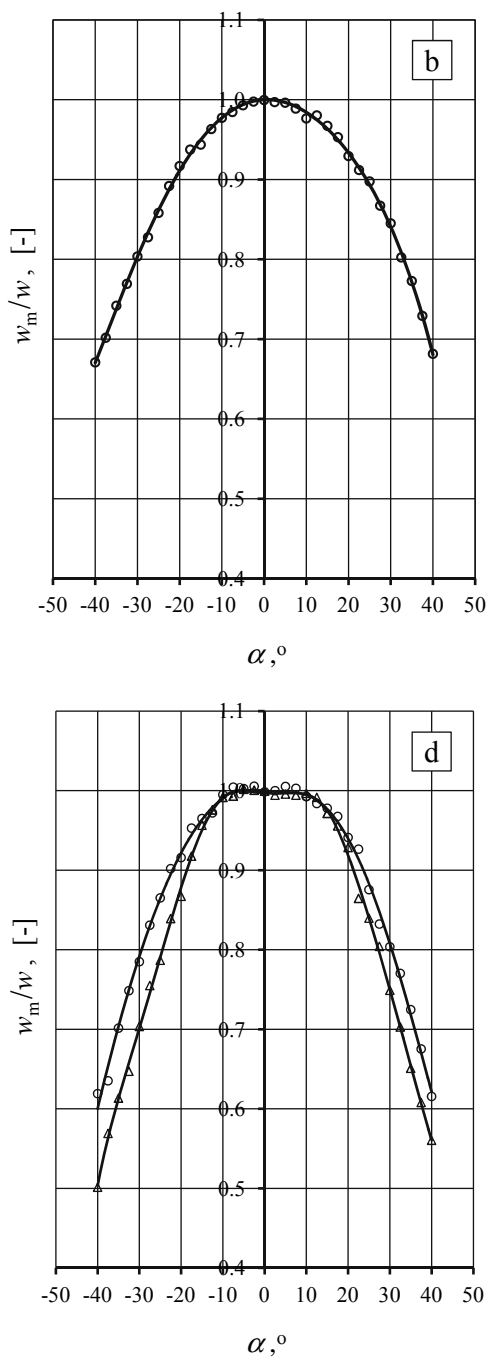

Fig. 10. Relative measured velocity $w_{\mathrm{m}} / w$ in relation to angle $\alpha$ for:

a - the probe with the aspiration nozzle $d_{\mathrm{a}}=16 \mathrm{~mm}$ and $w=7.7 \mathrm{~m} / \mathrm{s}$, at $\varepsilon=10 \%$ $\mathrm{b}$ - the probe with the aspiration nozzle $d_{\mathrm{a}}=16 \mathrm{~mm}$ and $w=10.9 \mathrm{~m} / \mathrm{s}$, at $\varepsilon=10 \%$ $\mathrm{c}$ - the probe with the aspiration nozzle $d_{\mathrm{a}}{ }^{2}=16 \mathrm{~mm}$ and $w=13.9 \mathrm{~m} / \mathrm{s}$, at $\varepsilon=10 \%$ $\mathrm{d}$ - the probe with the aspiration nozzle $d_{\mathrm{a}}=20 \mathrm{~mm}$ and $w=6.8 \div 6.9 \mathrm{~m} / \mathrm{s}$, at $\varepsilon=0.8 \%(\Delta)$ and $\varepsilon=10 \%(O)$ 
$w$ on their directional characteristic $w_{\mathrm{m}} / w=\mathrm{f}(\alpha)$. Measurements performed within the MSc thesis (Zembaty 2009) included observation of velocity values $w_{m}$ measured through the system with a given tube for variable velocity level $w=5,17$ and $29 \mathrm{~m} / \mathrm{s}$. Secondly, changes of intensity of turbulence in the tunnel system $\varepsilon: 0.8,10$ and $18 \%$ enabled the establishment of what influence on directional characteristics is possessed by turbulence intensity.

Testing results of S-type tubes for the case of $\varepsilon=10 \%$ in graphic form of dependence $w_{\mathrm{m}} / w=\mathrm{f}(\alpha)$ for three velocities of $w$, namely 5, 17 and $29 \mathrm{~m} / \mathrm{s}$, are presented in Figs $11 \mathrm{a}, \mathrm{b}$ and c. Measurements at the same three velocities $w$ were also conducted for a turbulence intensity $\varepsilon$ equal to $0.8 \%$ and $18 \%$. It was shown that in both cases of developed turbulence (10 and $18 \%$ ) the courses of $w_{\mathrm{m}} / w=\mathrm{f}(\alpha)$ are very flat (at the level of the value of 1.0) and indicate insignificant differences at variable velocity $w$. Only at turbulence $0.8 \%$ (and thus not typified with gas flows in industrial installations) and at low velocity $5 \mathrm{~m} / \mathrm{s}$ a somewhat different shape of the curve of $w_{\mathrm{m}} / w=\mathrm{f}(\alpha)$ was noted at the angle $\alpha$ greater than $25^{\circ}$. In connection with the above, the effect of averaging the curves obtained for the above quoted three $w$ velocities at the turbulence $\varepsilon=10 \%$ was assumed in the final data treatment to be the representation of the $w_{\mathrm{m}} / w=\mathrm{f}(\alpha)$ dependence for the S-type tube.

Fully analogous measurements were conducted for the L-type tube. They showed that at the investigated turbulence intensity values $\varepsilon: 0.8,10$ and $18 \%$ and also velocities $w: 5,17$ and $29 \mathrm{~m} / \mathrm{s}$ both of these parameters had no influence at all on the image of the characteristic $w_{\mathrm{m}} / w=\mathrm{f}(\alpha)$. In connection with the above, as representative for the L-type tube is assumed the dependence $w_{\mathrm{m}} / w=\mathrm{f}(\alpha)$ for $\varepsilon=10 \%$ and $w=17 \mathrm{~m} / \mathrm{s}$ (shown in Fig. 11d) and this is given a final treatment.

\section{Final results}

As referred to in the previous section, as final, representative for gas flows in industrial installations, the results of quotient $w_{\mathrm{m}} / w$ obtained at turbulence intensity $\varepsilon=10 \%$ were assumed. The final variation of this quotient together with angle $\alpha$, that is directional sensitivity, of the studied velocity sensors is shown in Figs 12 and 13.
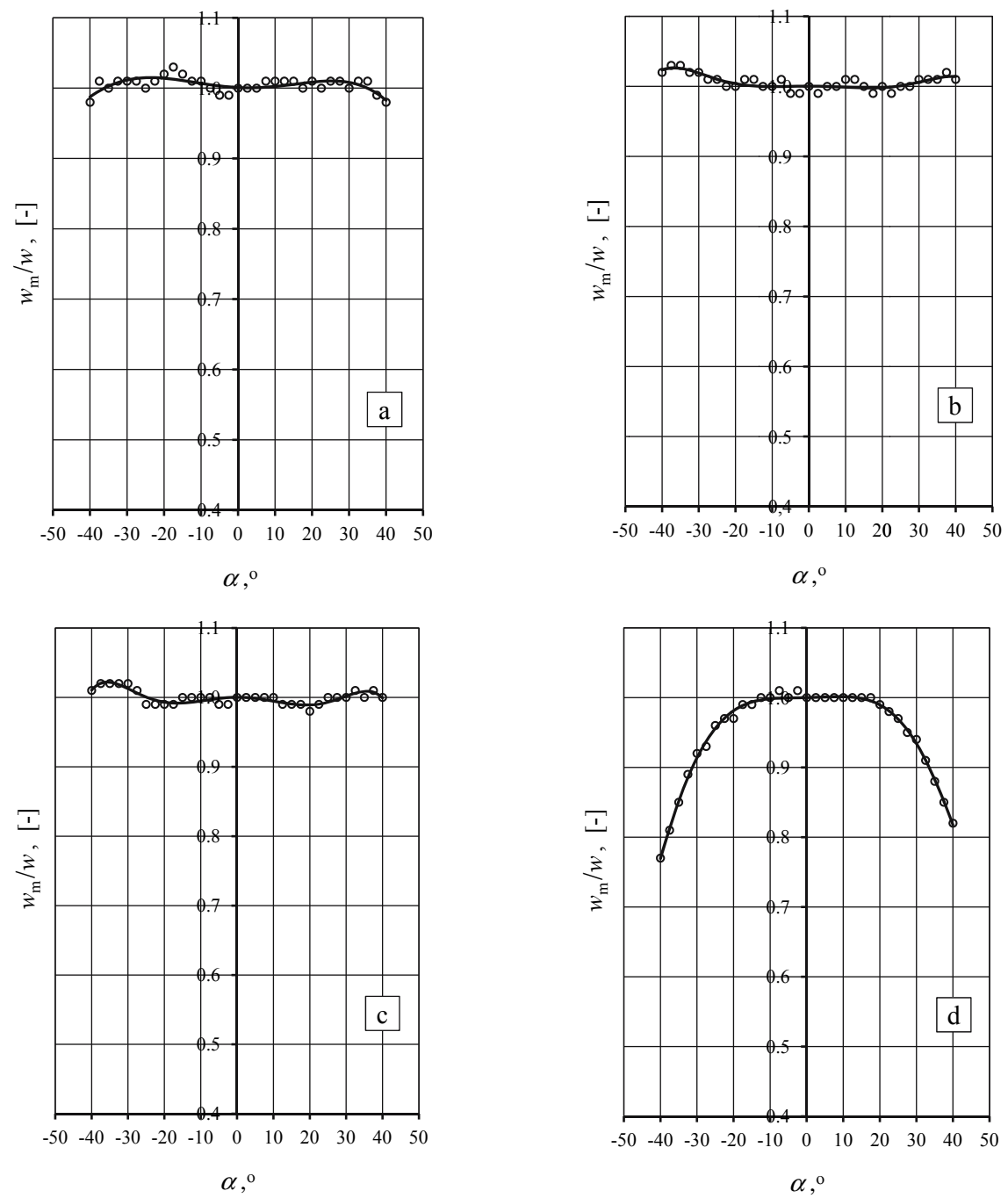

Fig. 11. Relative measured velocity $w_{\mathrm{m}} / w$ in relation to angle $\alpha$ for:

a - the S-type tube and $w=5 \mathrm{~m} / \mathrm{s}$, at $\varepsilon=10 \%$

$\mathrm{b}$ - the S-type tube and $w=17 \mathrm{~m} / \mathrm{s}$, at $\varepsilon=10 \%$

$c$ - the S-type tube and $w=29 \mathrm{~m} / \mathrm{s}$, at $\varepsilon=10 \%$

$\mathrm{d}$ - the L-type tube and $w=17 \mathrm{~m} / \mathrm{s}$, at $\varepsilon=10 \%$ 

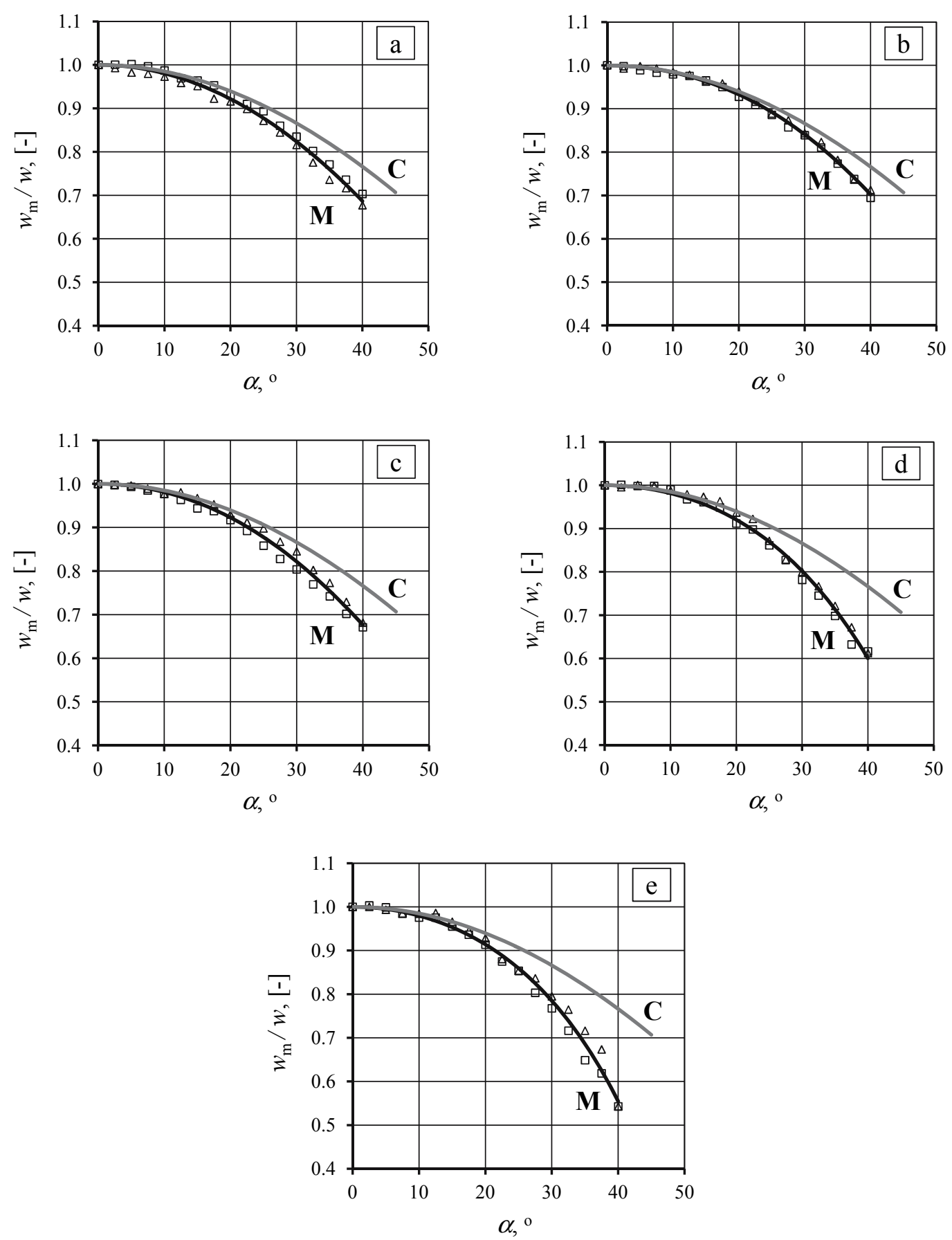

Fig. 12. Relative measured velocity $w_{\mathrm{m}} / w$ in relation to one-sided angle $\alpha$ (or directional sensitivity) against a background of relative actual axial velocity (or $\cos \alpha$ ) for the P-10ZA dust sampler probe

$\Delta$ - experimental points for positive angles, $\square$ - experimental points for negative angles, line $\mathbf{M}$ - approximation of experimental data, line $\mathbf{C}-\cos \alpha$

$\mathrm{a}-$ for the nozzle $d_{\mathrm{a}}=10 \mathrm{~mm}, \mathrm{~b}-$ for the nozzle $d_{\mathrm{a}}=13 \mathrm{~mm}, \mathrm{c}-$ for the nozzle $d_{\mathrm{a}}=16 \mathrm{~mm}, \mathrm{~d}-$ for the nozzle $d_{\mathrm{a}}=20 \mathrm{~mm}$, e - for the nozzle $d_{\mathrm{a}}=25 \mathrm{~mm}$

Concerning the curves $w_{\mathrm{m}} / w=\mathrm{f}(\alpha)$ for the zero pressure probe nozzles, a certain, insignificant asymmetry is shown (which may be seen for example in Fig. 10 for nozzle $d_{\mathrm{a}}=16 \mathrm{~mm}$ ); it is most probably in the first place the effect of less than the ideal construction of nozzles, and maybe also the non-ideal setting of nozzles during the testing. Both halves of point course of $w_{\mathrm{m}} / w=\mathrm{f}(\alpha)$, i.e. for negative and positive angle $\alpha$ values, are shown in Fig. 12 (a, b, c, d and e - for all nozzles) on one side; they were averaged and approximated with a continuous line, and the curve $\mathbf{M}$ was obtained in this manner. The values of angle $\alpha$ on this diagram should be treated both as positive and negative. Marked also is the course of relative axial velocity $w_{0} / w=\cos \alpha$ in the form of curve $\mathbf{C}$. Discrepancy between both these curves reflects the error that occurs between the measured velocity $w_{\mathrm{m}}$ obtained and the wanted axial velocity $w_{0}$. Obviously it refers to the situation when the zero pressure probe head (as a velocity sensor) is set aligned with the conduit as described in the introduction 

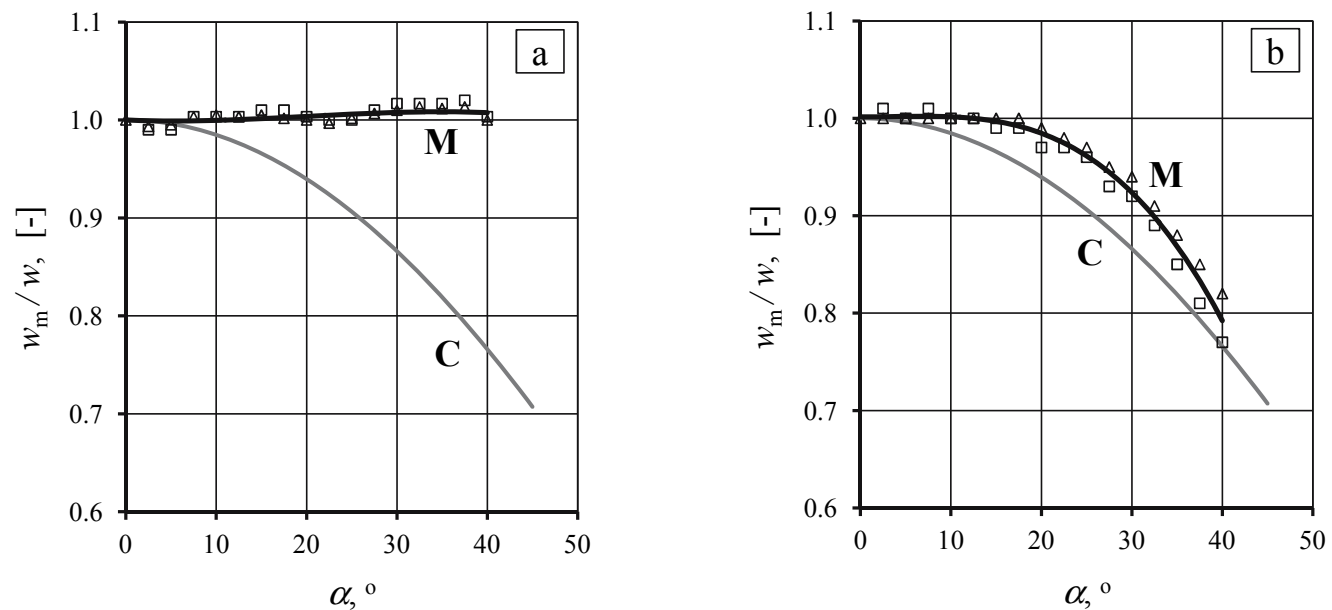

Fig. 13. Relative measured velocity $w_{m} / w$ in relation to one-sided angle $\alpha$ (or directional sensitivity) against a background of relative actual axial velocity (or $\cos \alpha$ ) for the impact-pressure tubes

$\Delta$ - experimental points for positive angles, $\square$ - experimental points for negative angles, line $\mathbf{M}$ - approximation of experimental data, line $\mathbf{C}-\cos \alpha$

a - the S-type tube, b - the L-type tube

as well as when gas flows non-coaxially, i.e. at a defined angle $\alpha$. The course of curves $\mathbf{M}$ in Fig. 12 signifies the formation of a measurement error of value of velocity vector $w$. For example, in angle $25^{\circ}$ it amounts for the all nozzles considered collectively to approx. $-(11 \div 14) \%$; this arises from reading the values $w_{\mathrm{m}} / w$ according to curve $\mathbf{M}$ in Fig. 12a-e: $0.859 \div 0.892$.

In the case of the S-type impact-pressure tube, the picture of curves $\mathbf{M}$ and $\mathbf{C}$ is shown in Fig. 13a. Here the final measurement data $w_{\mathrm{m}} / w$ for positive angles are - on account of the minor differences mentioned in the previous section in $w_{\mathrm{m}} / w$ with variable velocities $w$ - the effect of averaging the curves for three examined levels of velocity $w$ presented previously in Fig. 11a-c. The process is the same for negative angles. Such as for the zero pressure probe, the $\mathbf{M}$ curve was obtained by averaging almost symmetrical data for negative and positive angles, and next by approximating them for a continuous function. Observing the $\mathbf{M}$ curve confirms the known fact of weak directional measurement sensitivity of actual $w$ velocity in S-type tubes. For the tested tube, its example inclination of $25^{\circ}$ gives a positive error of measurement of the velocity vector $w$ magnitude of almost $1 \%$, which originates from reading the $w_{\mathrm{m}} / w$ value according to the $\mathbf{M}$ curve equal to 1.006 .

In the case of the L-type impact-pressure tube, the image of curves $\mathbf{M}$ and $\mathbf{C}$ is presented in Fig. 13b. The final discrete measurement data $w_{\mathrm{m}} / w$ are the result of averaging insignificantly asymmetrical data for negative and positive angles. The curve $\mathbf{M}$ was obtained by approximating these final measurement data to continuous function. Observation of the $\mathbf{M}$ curve itself confirms the known fact of the weak directional measurement of actual velocity $w$ of L-type tubes. For the examined tube, its example deviation $20^{\circ}$ gives a negative error measurement of velocity vector value $w$ of almost $2 \%$, which originates from reading the $w_{\mathrm{m}} / w$ value according to curve $\mathbf{M}$ equal to 0.982 .

Curves $\mathbf{M}$ and $\mathbf{C}$ on graphs in Figs 12 and 13 became the basis of calculation of the error in determining the axial velocity with the aid of the three examined sensors. The calculation formula of this error appearing in equation 3, namely $\delta=\left(w_{\mathrm{m}} / w\right) / \cos \alpha-1$, indicates that the sought-after relation $\delta=\mathrm{f}(\alpha)$ is de facto the result of use of the values of function $\mathbf{M}$ and function $\mathbf{C}$ in the following manner:

$$
\delta=\mathbf{M} / \mathbf{C}-1=\mathrm{f}(\alpha)
$$

Such an operation was performed on the ordinates of both the functions, and subsequently continuous courses of $\delta=\mathrm{f}(\alpha)$ were obtained, which are presented in Fig. 14. Analysis of formation of error $\delta$ leads to the following inferences.

\section{Conclusions}

If in the flue gas conduit of an industrial installation, directional deformity of gas velocity vector occurs only in a plane parallel to the conduit axis and the measurement of velocity distribution is conducted by a sensor with the head placed also parallel to the conduit axis, then between readings of the measurement velocity values $w_{\mathrm{m}}$ and the sought-after axial velocity $w_{0}$ the (relative) error $\delta$ described below appears on the examined sensors. It results from: $1^{\circ}$ the proved variability together with angle $\alpha$ (defining the direction of gas flow with regard to the conduit axis) shown in Fig. 14, and $2^{\circ}$ essential knowledge of a team performing measurements of precise or potential values of angle $\alpha$ at particular points of the measuring section.

a. In measurements using the zero pressure dust sampling probe (with anemometric function), the error $\delta$ is formed according to the dependence shown in Fig. 14a. It varies for particular aspiration nozzles. If these variations would not be investigated and the most extreme error for the probe as a whole would be sought, then the values of this error: $-0.4 \%,-1.4 \%,-3.0 \%$ and $-9.5 \%$ may be assumed for the example of the following gas flow angles of: $5^{\circ}, 10^{\circ}, 15^{\circ}$ and $30^{\circ}$.

b. In measurements performed with the aid of the S-type impact-pressure tube, the error $\delta$ is shaped according to dependence shown in Fig. 14b. For example: for inflowing 

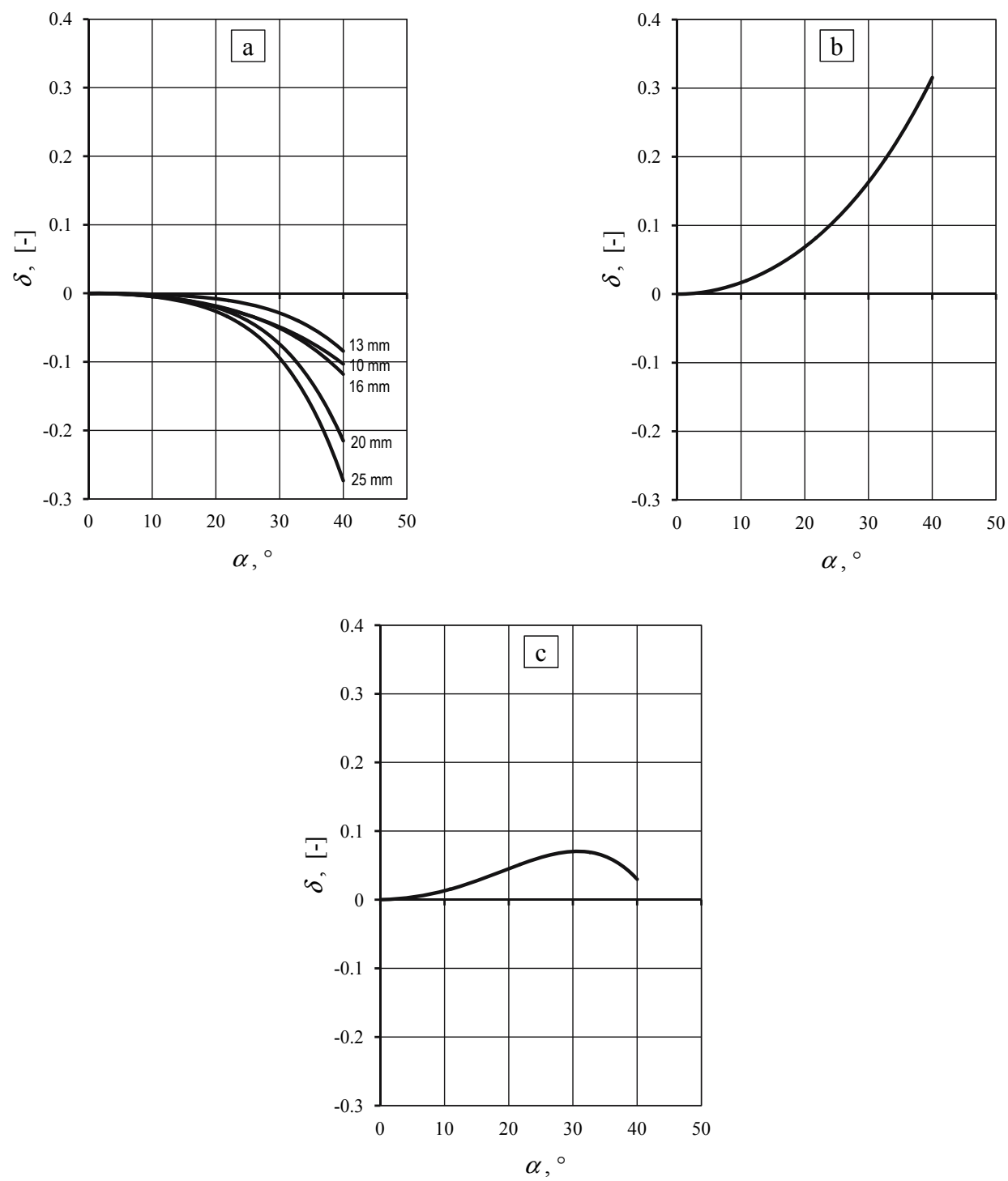

Fig. 14. Relative error $\delta$ of determination of axial velocity $w_{0}$ in situation of deviated local gas flow and setting the velocity sensor coaxially with the conduit for:

a - the P-10ZA zero pressure dust sampling probe with its five nozzles of mentioned diameter $d_{\mathrm{a}}$, b - the S-type tube, c - the L-type tube

gas at angles: $5^{\circ}, 10^{\circ}, 15^{\circ}$ and $30^{\circ}$, the error amounts, appropriately, to: $+0.4 \%,+1.7 \%,+3.8 \%$ and $+16.3 \%$.

c. In measurements performed with the aid of the L-type impact-pressure tube, the error $\delta$ is shaped according to the dependence shown in Fig. 14c. For example: for inflowing gas at an angle of: $5^{\circ}, 10^{\circ}, 15^{\circ}$ and $30^{\circ}$, the error amounts to, correspondingly: $+0.3 \%,+1.3 \%,+2.8 \%$ and $+7.0 \%$.

Knowledge of the axial velocity error, contained in the diagrams in Fig. 14 and exemplified in the above quoted values, may be used, for example, in two ways (depending on what data is possessed): $1^{\circ}$ if one knows the gas inflow angle exactly at a given point, one may eliminate that error and calculate the sought-after axial velocity according to the relationship $w_{0}=w_{\mathrm{m}} /(\delta+1)$, in which $\delta$ appears with a value read out for the given angle; $2^{\circ}$ if, e.g., the maximum angle of gas inflow in the entire section is estimated then the read-out value of the maximum error corresponding to this angle may serve in appropriate procedures (not being the subject of this article), for determination of the expected value of $w_{0}$ (remaining in a definite relation to $w_{\mathrm{m}}$ ) together with its calculated measurement uncertainty (at a given confidence level).

The above shown material (both the experimental data and the proposals for its use) refer - as it is clearly defined at the beginning of the article - to a certain group of flow issues, namely regarding the two-dimensional deformation of velocity profile of gas in flue gas conduits of industrial installations. Even then, however, great technical difficulties occur in the precise determination of the gas flow angle at many particular measuring section points, when common differential pressure velocity sensors are applied. Furthermore, if a measurement team decides to admit a particular flow to be a two-dimensional deformation issue, they do it in the process of certain but not always easy estimation or approximation. The level of the error itself at an angle exceeding $15^{\circ}$ (which may reach several or over a dozen per cent) makes for a considerable uncertainty in the determination of the axial velocity. Finally, most difficulties are caused by the inability to find or estimate the inflow angle of gas in cases of three-dimensional deformation (with the use of the above- 
-mentioned common sensors). Actually, for such deformations, directional sensitivities are unknown and would be very difficult to establish in the laboratory. From these observations comes the comment on the need for developing a velocity sensor, enabling the establishment of values of velocity $w_{0}$ - as an axial component of vector $w-$ and angle $\alpha$ in three-dimensional space. Such a sensor should be introduced into ordinary measurement practice and hence into relevant standard regulations.

\section{Symbols}

$A$ - conduit cross-sectional area

$\beta-$ empirical shape factor

$d_{\mathrm{a}}-$ diameter of aspiration nozzle of the zero pressure dust sampling probe

$E$ - dust emission rate (mass flow rate of dust emitted) to the atmosphere

$s \quad-$ (mass) concentration of dust in a flue gas plant, at the outlet to the atmosphere

$\dot{V} \quad$ - gas volume flow rate in a flue gas plant, at the outlet to the atmosphere

$w$ - velocity (magnitude of velocity vector) of gas at a given point in a conduit; reference velocity in the tests

$w_{0}$ - axial velocity of gas, along the conduit axis

$w_{\mathrm{m}}$ - measured gas velocity, by the measuring system of examined sensor

$\bar{w}-$ average velocity in a conduit cross-section

$\alpha$ - angle between the axis of the sensor head (identified with the conduit axis) and the gas flow direction

$\delta-$ relative error in determination of the axial velocity (dimensionless)

$\varepsilon \quad-$ intensity of turbulence of gas flowing in the conduit/wind tunnel (dimensionless)

$\Delta p$ - measuring pressure difference of the investigated zero pressure dust sampling probe or investigated impact-pressure tube

$\Delta p_{\mathrm{c}}$ - measuring pressure difference in a control impact-pressure microtube

\section{Acknowledgments}

The research reported in this article was conducted within the work BK-276/RIE-1/2013 "Research on indoor environment engineering elements and systems and dust content measurement".

\section{References}

Dwyer (www.dwyer-inst.com (15.08.2013)).

EN (2001). EN 13284-1:2001 Stationary source emissions - Determination of low range mass concentration of dust - Part 1: Manual gravimetric method.

EN ISO (2013). EN ISO 16911-1:2013 Stationary source emissions - Manual and automatic determination of velocity and volume flow rate in ducts - Part 1: Manual reference method.

Goldstein, R.J. (1983). Fluid Mechanics, Hemisphere Publishing Corp., Washington 1983.

ISO (2008). ISO 3966:2008 Measurement of fluid flow in closed conduits - Velocity area method using Pitot static tubes.

ISO (2003). ISO 9096:2003 Stationary source emissions - Manual determination of mass concentration of particulate matter.
ISO (1994). ISO 10780:1994 Stationary source emissions - Measurement of velocity and volume flowrate of gas streams in ducts.

ISO (2013). ISO 16911-1:2013 Stationary source emissions - Manual and automatic determination of velocity and volume flow rate in ducts - Part 1: Manual reference method.

Kabza, Z. \& Kostyrko, K. (2003). Metrology of indoor microclimate and environmental physical quantities. Part 1, Publishing House of the Opole University of Technology, Opole 2003. (in Polish)

Kateusz, P. (2000). Research on effect of gas stream turbulence on the accuracy of velocity measurement with differential pressure type sensors, Ph.D. thesis, Silesian University of Technology, Gliwice 2000. (in Polish)

Kateusz, P., Popiołek, Z. \& Szulikowski, J. (2001). Uncertainty of flue gas velocity measurement by means of the cylindrical and S-type Pitot tubes due to the turbulence impact on their calibration constant, Proceedings of the 7 th National Symposium "Fluid Mechanics Applications in Environmental Engineering", Gliwice-Wisła 2001. (in Polish)

Kateusz, P., Popiołek, Z. \& Szulikowski, J. (2004). Gas flow turbulence impact on anemometric characteristics of aspiration probes of gravimetric samplers, Archives of Environmental Protection, 30, 1, pp. 43-49. (in Polish)

Kołodziejczyk, L., Rubik, M. \& Mańkowski, S. (1974). Measurements in Sanitary Engineering, Arkady, Warszawa 1974. (in Polish)

Necati, G.A. (1988). Technique of experimental research and measurements, in: Automotive Aerodynamics. From Fluid Mechanics to Vehicle Construction, Hucho, W.H. (Ed.), Wydawnictwo Komunikacji i Łączności, Warszawa 1988. (in Polish)

Ower, E. \& Pankhurst, R.C. (1977). The measurement of air flow, Pergamon Press, Oxford 1977.

PN-EN (2007). PN-EN 13284-1:2007P Stationary source emissions - Determination of low range mass concentration of dust - Part 1: Manual gravimetric method. (in Polish)

PN-EN ISO (2013). PN-EN ISO 16911-1:2013-07E Stationary source emissions - Manual and automatic determination of velocity and volume flow rate in ducts - Part 1: Manual reference method. (in Polish)

PN (1994). PN-Z-04030-7:1994P Air purity protection - Tests for dust content - Measurement of concentration and mass flow rate of particulate matter in waste gases by gravimetric method. (in Polish)

Tracz, A. (2003). Research on directional sensitivity of a zero-pressure type probe as a gas velocity sensor in the P-10ZA gravimetric dust sampler, MSc thesis, supervisor: J. Szulikowski, Silesian University of Technology, Gliwice 2003. (in Polish)

Zembaty, M. (2009). Research on directional sensitivity of the selected Pitot tubes, MSc thesis, supervisor: J.Szulikowski, Silesian University of Technology, Gliwice 2009. (in Polish)

Report (1979). Report EPA-660/4-79-042 (1979) Angular Flow Insensitive Pitot Tube Suitable for Use with Standard Stack Testing Equipment (from: www.epa.gov).

Szulikowski, J. \& Kateusz, P. (2009). Measuring gas velocity in a duct as a specific function of a pressure balance type probe in an isokinetic dust sampler, Environmental Technology, 30, 3, pp. 301-311.

Test-Therm, (www.test-therm.com.pl (12.08.2013)). (in Polish)

Troskolański, A.T. (1969). Hydromechanics, Wydawnictwa Naukowo-Techniczne, Warszawa 1969. (in Polish) 


\section{Czułość kierunkowa różnicowo-ciśnieniowych czujników prędkości gazu stosowanych w manualnych pomiarach grawimetrycznych emisji zanieczyszczeń pyłowych ze źródeł stacjonarnych}

Streszczenie: Na potrzeby określania emisji zanieczyszczeń pyłowych do atmosfery z przemysłowych instalacji technologicznych często wykonywane są manualne pomiary rozkładu prędkości gazu w kanałach instalacji gazów odlotowych przy pomocy układów z różnicowo-ciśnieniowymi czujnikami prędkości. Celem jest ustalenie profilu prędkości osiowej. Przepływy w przekrojach pomiarowych nie zawsze są współosiowe z biegiem kanału; cechują się różnymi kierunkami wektora prędkości w różnych punktach pomiarowych. Ustalanie rzeczywistych kierunków wektorów prędkości lokalnych, dające gwarancję dokładnego obliczenia prędkości osiowych, często nie jest możliwe z technicznego punktu widzenia i pomiar prędkości prowadzi się przy ustawieniu głowicy czujnika równoległym w stosunku do osi i ścian kanału. Wtedy wiedza o czułości kierunkowej zastosowanego czujnika prędkości pozwala albo na wyeliminowanie błędu pomiaru prędkości osiowej, albo na uwzględnienie go poprzez niepewność tego pomiaru. Dla specyficznych sytuacji dwuwymiarowej zmienności kierunku wektora prędkości wyznaczono charakterystyki czułości kierunkowej i w konsekwencji charakterystyki błędu trzech przyjętych do badań czujników: pyłowej sondy zerowej o funkcji anemometrycznej jako elementu pyłomierza grawimetrycznego i porównawczo - dwóch powszechnie stosowanych rurek spiętrzających: typu S i L. 